\title{
Mechanism of glycyrrhizin on ferroptosis during acute liver failure by inhibiting oxidative stress
}

\author{
YAO WANG, QIAN CHEN, CHUNXIA SHI, FANGZHOU JIAO and ZUOJIONG GONG \\ Department of Infectious Diseases, Renmin Hospital of Wuhan University, Wuhan, Hubei 430060, P.R. China
}

Received April 15, 2019; Accepted August 5, 2019

DOI: $10.3892 / \mathrm{mmr} .2019 .10660$

\begin{abstract}
The present study aimed to investigate the anti-ferroptosis effects of the HMGB1 inhibitor glycyrrhizin (GLY). The present study used a cell and animal model of acute liver failure (ALF), induced using tumor necrosis factor- $\alpha$, lipopolysaccharide and D-galactosamine, to investigate the effects of GLY. The expression of glutathione peroxidase 4 (GPX4) and high mobility group protein B1 (HMGB1), heme oxygenase-1 (HO-1) and nuclear factor erythroid 2-related factor 2 ( Nrf2) were detected were detected by western blotting in L02 hepatocytes and mouse liver. The expression of GPX4 and HMGB1 in L02 hepatocytes and mouse liver was detected by immunofluorescence. The pathological changes to liver tissues were determined by hematoxylin and eosin staining. The levels of lactate dehydrogenase (LDH), $\mathrm{Fe}^{2+}$, reactive oxygen species (ROS) and glutathione (GSH) were tested using kits. Compared with the normal group, the degree of liver damage and liver function in the model animal group was severe. The protein levels of HMGB1 in L02 cells and liver tissues were significantly increased. The expression of NRF2, HO-1 and GPX4 was significantly decreased. The levels of $\mathrm{LDH}, \mathrm{Fe}^{2+}$, malondialdehyde (MDA) and ROS were increased, whereas the level of GSH was decreased. Treatment with GLY reduced the degree of liver damage, the expression of HMGB1 was decreased, and the levels of Nrf2, HO-1 and GPX4 were increased. The levels of $\mathrm{LDH}, \mathrm{Fe}^{2+}$, MDA, ROS were decreased, while the level of GSH was increased by GLY treatment. The results of the present study indicated that HMGB1 is involved in the process of ferroptosis. The HMGB1 inhibitor GLY significantly reduced the degree of ferroptosis during ALF by inhibiting oxidative stress.
\end{abstract}

Correspondence to: Professor Zuojiong Gong, Department of Infectious Diseases, Renmin Hospital of Wuhan University, 238 Jiefang Road, Wuhan, Hubei 430060, P.R. China

E-mail: zjgong@163.com

Key words: glycyrrhizin, ferroptosis, acute liver failure, oxidative stress, reactive oxygen species

\section{Introduction}

Acute liver failure (ALF) is a serious disorder or decompensation caused by various factors, including liver synthesis, detoxification, excretion and biotransformation, and the mortality rate of ALF caused by hepatitis B virus (HBV) is more than $50 \%$ in China (1). Enterogenous endotoxemia plays an important role in the development and prognosis of ALF (2). When the intestinal flora is disturbed during ALF, intestinal mucosal damage and intestinal bacterial translocation occur. Gram-negative bacteria or their products can be transferred from the intestinal lumen to the circulatory system, causing an inflammatory response in the liver and inducing the necrosis of hepatocytes (3).

As a novel type of necrosis, ferroptosis was described by Dixon et al (4) in 2012. Ferroptosis is characterized by intracellular iron ion accumulation, elevated lipid peroxidation, mitochondria and mitochondrial membrane density. Oxidative stress is the key pathogenic link with ALF and could promote ALF (5). Ferroptosis is also characterized by the accumulation of reactive oxygen species (ROS) under high oxidative stress. Therefore, if ferroptosis can be inhibited, ALF may be effectively alleviated.

Glycyrrhizin (GLY) is the main extract from the glycyrrhiza root and is an important compound (6). Its molecular formula is $\mathrm{C}_{42} \mathrm{H}_{62} \mathrm{O}_{16}$ (7). It has been reported that GLY has anti-oxidative, anti-inflammatory, anti-virus activities, as well as anti-fibrotic activity in the liver, and that GLY can inhibit tumor growth and enhance immunity (8-11). GLY is a natural antioxidant that has a protective effect on the liver and is widely used in the treatment of chronic hepatitis (12).

However, whether GLY can alleviate ferroptosis in ALF requires further study. In the present study, tumor necrosis factor- $\alpha$ (TNF- $\alpha$ ), lipopolysaccharide (LPS) and D-galactosamine (D-GalN) were used to stimulate L02 hepatocytes and mice in order to construct a cellular and mouse model of ALF. GLY was administered to these ALF models to evaluate the degree of ferroptosis, and the corresponding pathway changes, in hepatocytes.

\section{Materials and methods}

Reagents. The normal human liver cell line (L02) was purchased from The Cell Collection Center of Wuhan University. The Cell Counting Kit-8 (CCK-8) assay was 
purchased from Dojindo Chemical Technology Co., Ltd. GLY was purchased from Selleck Chemicals. The lactate dehydrogenase (LDH), malondialdehyde (MDA), glutathione (GSH) and ROS kits were purchased from Beyotime Institute of Biotechnology. The primary antibodies against glutathione peroxidase 4 (GPX4, cat. no. sc-166570) was purchased from Santa Cruz Biotechnology ,Inc. GAPDH (cat. no. 10494-1-AP) were purchased from ProteinTech Group, Inc. The primary antibodies against high mobility group box 1 (HMGB1, cat. no. 3935), nuclear factor E2-related factor 2 (Nrf2, cat. no. 12721) and homooxygenase-1 (HO-1, cat. no. 43966) were purchased from Cell Signaling Technology, Inc. The goat anti-rabbit IRDye fluorescent secondary antibody IRDye800CW (cat. no. 926-32211) was purchased from LI-COR Biosciences. Cy3 (cat. no. BA1031 and BA1032) and FITC (cat. no. BA1101 and BA1105) fluorescently labeled rabbit anti-goat secondary antibodies were purchased from Wuhan Boster Biological Technology, Ltd. The iron ion detection kit was purchased from Abcam. D-GalN, LPS and TNF- $\alpha$ were purchased from Sigma-Aldrich; Merck KGaA.

Cell culture and drug intervention. L02 cells were cultured in DMEM (Gibco; Thermo Fisher Scientific, Inc.) containing 10\% fetal bovine Serum (FBS, Gibco; Thermo Fisher Scientific, Inc.) The cells were cultured at $37^{\circ} \mathrm{C}$ in an incubator with $5 \%$ $\mathrm{CO}_{2}$. When cells reached a confluency of $70-80 \%$, cells were digested with trypsin and seeded into $6-\left(1.5 \times 10^{6}\right.$ cells $/ 1.5 \mathrm{ml}$ DMEM per plate) or 96 -well $\left(5 \times 10^{3}\right.$ cells $/ 100 \mu$ l DMEM per plate) plates. The cells were divided into five groups as follows: The normal group, model group, GLY $0.5 \mathrm{mM}$ intervention group, GLY $1 \mathrm{mM}$ intervention group and GLY $2 \mathrm{mM}$ intervention group. The GLY intervention groups were stimulated with the corresponding concentration of GLY for $2 \mathrm{~h}$ at $37^{\circ} \mathrm{C}$ in advance of further treatment. After $2 \mathrm{~h}, \mathrm{TNF}-\alpha(100 \mathrm{ng} / \mathrm{ml})$ and D-GalN (44 $\mu \mathrm{g} / \mathrm{ml})$ was added to the cells in the model group and GLY intervention groups for $24 \mathrm{~h}$. The cells and supernatant were collected for subsequent experimental testing.

Animal model preparation. In total, 40 male specificpathogen-free C57BL/6 mice (Hubei Animal Experimental Center) 6-8 weeks old and weighing 20-25 g were housed in the animal experiment center in Renmin Hospital of Wuhan University with $12 \mathrm{~h} \mathrm{light/dark} \mathrm{cycle,} \mathrm{temperature} \mathrm{of} 25 \pm 2^{\circ} \mathrm{C}$ and relative humidity of $50 \pm 15 \%$. All mice were provided with food and water ad libitum. The mice were randomly divided into 5 groups: The normal group, model group, $15 \mathrm{mg} / \mathrm{kg}$ GLY group, $30 \mathrm{mg} / \mathrm{kg}$ GLY group and $60 \mathrm{mg} / \mathrm{kg}$ GLY group. Except for the normal group, the other four groups of mice were injected intraperitoneally with D-GalN $(400 \mathrm{mg} / \mathrm{kg})$ and LPS $(100 \mu \mathrm{g} / \mathrm{kg})$ to induce the ALF model. According to a previous study on GLY gavage doses (13), three doses of GLY $(15,30$ and $60 \mathrm{mg} / \mathrm{kg} / \mathrm{day})$ intervention groups were used. A total of 24 mice were divided into three groups. Mice received gavage with different doses of GLY for 3 days before induction of the ALF model. The ALF model group received the same amount of isotonic saline. After $24 \mathrm{~h}$, the liver tissues were removed. The serum was collected to determine the levels of alanine aminotransferase (ALT), aspartate aminotransferase (AST) and total bilirubin (TBIL) by using a fully automatic biochemical analyzer (ADVIA 2400, Siemens AG). The present study was approved by the Institutional Animal Care and Use Committee of Renmin Hospital of Wuhan University.

CCK-8 detection of cell viability. L02 cells were uniformly seeded in a 96-well plate at a density of $5 \times 10^{3}$ cells $/ 100 \mu 1$ in DMEM with different concentrations of GLY $(0,0.5,1$ and $2 \mathrm{mM}$ ). According to the manufacturer's protocol, $10 \mu \mathrm{lCCK}-8$ reagent was added to each well after $24 \mathrm{~h}$. After mixing, the optical density (OD) for each well was measured using a microplate reader. Cell viability was calculated according to the following formula: Cell viability $=(\mathrm{OD}$ value of experimental group-OD value of blank control group)/(OD value of normal group-OD value of blank control) x100.

$L D H, M D A, \mathrm{Fe}^{2+}, \mathrm{ROS}$ and GSH levels in the LO2 cell line and liver tissues. The LDH, MDA, $\mathrm{Fe}^{2+}$, ROS and GSH kits were performed according to the manufacturers' protocols. The values for the levels of $\mathrm{LDH}, \mathrm{MDA}, \mathrm{Fe}^{2+}$, ROS and GSH in the cells, cell supernatant and liver tissues were measured using a microplate reader at the absorption wavelengths of 490, 532, 593, 490 and $412 \mathrm{~nm}$.

Western blotting and immunofluorescence detection of protein expression. The cells or liver tissues were homogenized by radio immunoprecipitation assay (RIPA) lysis buffer (Beyotime Institute of Biotechnology) on ice to extract total protein. Protein concentration was determined by bicinchoninic acid (BCA) protein assay reagent assay kit (Beyotime Institute of Biotechnology). Protein lysates $(30 \mu \mathrm{g})$ were subjected to $12 \%$ SDS-PAGE. The proteins were transferred to PVDF membranes (EMD Millipore). After blocking with 20\% non-fat milk at room temperature for $1 \mathrm{~h}$, the membranes were incubated with primary antibodies against GPX4 $(1: 1,000)$, Nrf2 $(1: 1,000)$, HO-1 (1:1,000), HMGB1 $(1: 1,000)$ and GAPDH $(1: 1,000)$ overnight at $4^{\circ} \mathrm{C}$. The IRDye $800 \mathrm{CW}$ secondary antibody $(1: 10,000)$ was incubated at $37^{\circ} \mathrm{C}$ for $1 \mathrm{~h}$. The protein bands were visualized using the Odyssey Infrared Imaging System (version 3.0, LI-COR Biosciences).

For immunofluorescence, circular slides were placed in 24-well plates and were seeded with $1 \times 10^{4} \mathrm{~L} 02$ cells/400 $\mu 1$ DMEM per plate. After treatments, the slides were fixed with $4 \%$ paraformaldehyde at $37^{\circ} \mathrm{C}$ for $30 \mathrm{~min}$, permeabilized with $0.2 \%$ Triton X-100 (Beyotime Institute of Biotechnology) at $37^{\circ} \mathrm{C}$ for $20 \mathrm{~min}$, blocked with $5 \%$ bovine serum albumin (BSA, Beijing Solarbio Science \& Technology Co., Ltd.) at $37^{\circ} \mathrm{C}$ for $30 \mathrm{~min}$ and incubated with primary antibodies against HMGB1 (1:100) and GPX4 (1:100) at $4^{\circ} \mathrm{C}$ overnight. Slides were then incubated with $\mathrm{Cy} 3$ and FITC-labeled fluorescent secondary antibodies $(1: 100)$ at $37^{\circ} \mathrm{C}$ for $1 \mathrm{~h}$ in dark room. Then the sections were stained with $5 \mu \mathrm{g} / \mathrm{ml}$ DAPI (Beyotime Institute of Biotechnology) at $37^{\circ} \mathrm{C}$ for $5 \mathrm{~min}$ in a dark room. The slides were observed under a fluorescence microscope at x200 magnification.

Hematoxylin and eosin $(H \& E)$ staining and immunofluorescence detection of liver tissue. Mouse liver tissues were fixed in $4 \%$ paraformaldehyde solution at $37^{\circ} \mathrm{C}$ for $24 \mathrm{~h}$ and embedded in paraffin, then sectioned at $5 \mu \mathrm{m}$ thickness. The sections were stained with Harris hematoxylin (Beyotime 
A

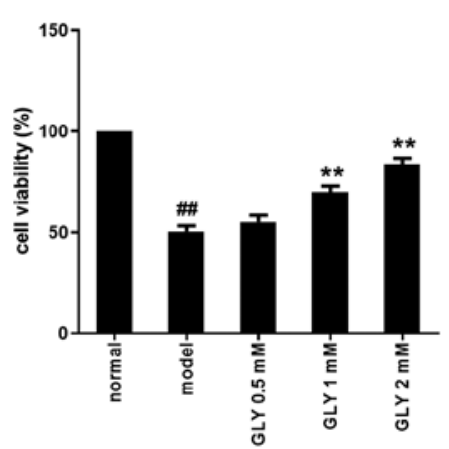

D

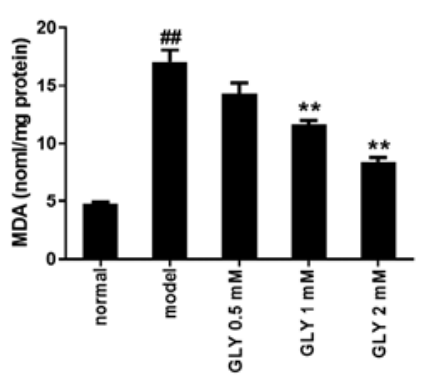

B

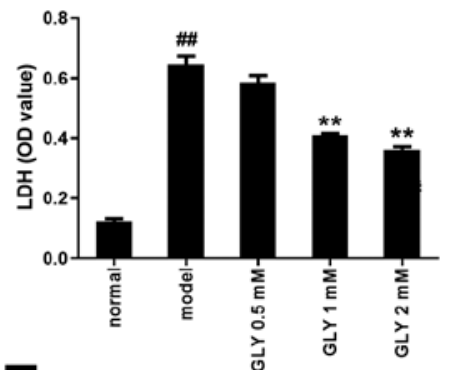

E

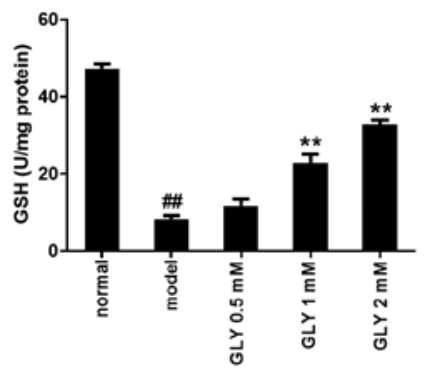

C

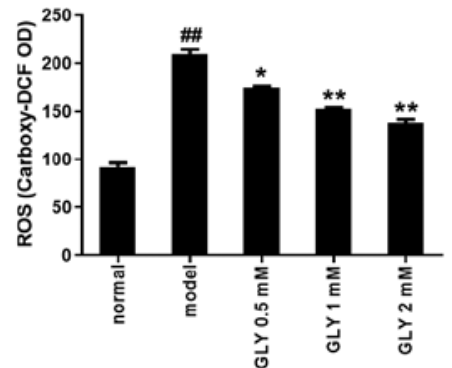

F

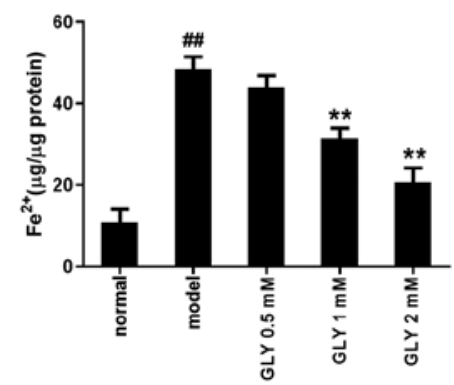

Figure 1. GLY decreased cell injury in TNF- $\alpha / \mathrm{D}-$ GalN induced L02 cells. (A) GLY increased cell viability in TNF- $\alpha / \mathrm{D}-\mathrm{GalN}$-induced L02 cells. GLY decreased the levels of (B) LDH, (C) ROS and (D) MDA, and (E) increased the level of GSH in TNF- $\alpha / \mathrm{D}-\mathrm{GalN}$-induced L02 cells. (F) GLY decreased the level of $\mathrm{Fe}^{2+}$ in TNF- $\alpha / \mathrm{D}-\mathrm{GalN}$ induced L02 cells. $\mathrm{n}=3 .{ }^{\# /} \mathrm{P}<0.01$ vs. normal; ${ }^{* *} \mathrm{P}<0.01,{ }^{*} \mathrm{P}<0.05$ vs. model. TNF- $\alpha$, tumour necrosis factor- $\alpha$; $\mathrm{D}-\mathrm{GalN}$, D-galactosamine; GLY, glycyrrhizin; LDH, lactate dehydrogenase; ROS, reactive oxygen species; MDA, malondialdehyde; GSH, glutathione; OD, optical density; carboxy-DCF, 6-carboxy-2',7'-dichlorodihydrofluorescein.

Institute of Biotechnology) at $37^{\circ} \mathrm{C}$ for $5 \mathrm{~min}$ and eosin $(95 \%$ ethanol preparation, Beyotime Institute of Biotechnology) at $37^{\circ} \mathrm{C}$ for $15 \mathrm{sec}$. After staining, the liver tissues were observed under a light microscope at x200 magnification. For the immunofluorescence detection of liver tissues, paraffin sections were dewaxed and hydrated, and immersed in citrate buffer for antigen retrieval. Sections were blocked with $5 \%$ $\mathrm{BSA}$ at $37^{\circ} \mathrm{C}$ for $30 \mathrm{~min}$, and incubated with GPX4 (1:200) and HMGB1 (1:200) antibodies at $4^{\circ} \mathrm{C}$ overnight. Slices were then incubated with the $\mathrm{Cy} 3$ and FITC-labeled secondary antibody at $37^{\circ} \mathrm{C}$ for $1 \mathrm{~h}$ in a dark room. DAPI $(5 \mu \mathrm{g} / \mathrm{ml})$ was used to stain nuclei at $37^{\circ} \mathrm{C}$ for $5 \mathrm{~min}$ in dark room. Finally, the slices were imaged under an inverted fluorescence microscope at x200 magnification.

Statistical analysis. All data are presented as the mean \pm SEM. Data were analyzed using SPSS 17.0 statistical software (SPSS, Inc.). All experiments were repeated three times. The differences among three or more groups were analyzed using one-way ANOVA followed by Bonferroni's post hoc test. $\mathrm{P}<0.05$ was considered to indicate a statistically significant difference.

\section{Results}

GLY enhances cell viability in TNF- $\alpha / D$-GalN-induced LO2 cells. The destruction of the cell membrane structure induced by ferroptosis causes the release of $\mathrm{LDH}$ in the cytoplasm into the culture medium. Therefore, the degree of liver damage can be determined by detecting the levels of $\mathrm{LDH}$ in the supernatant of cultured cells. As shown in Fig. 1A and B, when compared with the normal group, the cell viability in the L02 model group induced by TNF- $\alpha / \mathrm{D}-\mathrm{GalN}$ was significantly reduced, while the $\mathrm{LDH}$ level was significantly increased $(\mathrm{P}<0.01)$. Treatment with 1 or $2 \mathrm{mM}$ GLY increased cell viability and decreased the level of LDH compared with the model group $(\mathrm{P}<0.01)$.

GLY enhances the anti-oxidative capacity in TNF- $\alpha / D$ GalN-induced LO2 cells. ROS is the general term for a class of highly reactive compounds that are composed of oxygen, including oxygen free radicals and non-radical oxygenated products (14). ROS accumulate following adverse external stimuli and can exceed the scavenging ability of the peroxidase system, leading to oxidative stress, triggering lipid peroxidation, damage to the cell membrane and finally inducing ferroptosis (15). MDA is a product of lipid peroxidation. It has strong biological toxicity and its production can aggravate biofilm damage. Therefore, it is an index for membrane lipid peroxidation, which indirectly reflects the degree of damage to a cell (16). In order to validate the effect of GLY on the antioxidant capacity of a TNF- $\alpha / \mathrm{D}-\mathrm{GalN}$-induced L02 cell injury model, ROS and MDA levels were detected. As shown in Fig. 1C and D, when compared with the normal group, ROS and MDA levels in the model group were significantly increased $(\mathrm{P}<0.01)$. Treatment with GLY reduced the levels of ROS, MDA and LDH.

Effect of GLY on GSH and Fe $e^{2+}$ levels in TNF- $\alpha / D-G a l N-$ induced LO2 cells. GSH is an important non-enzymatic 
A

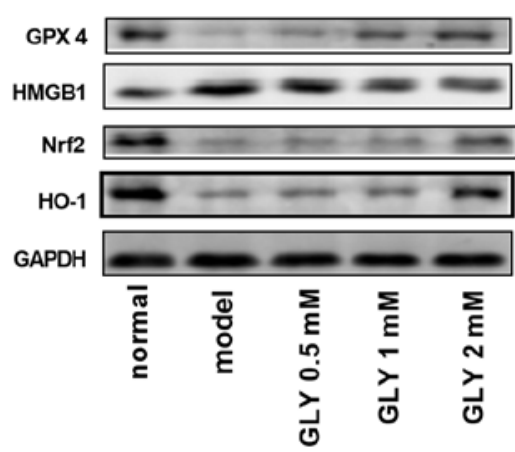

D DAPI
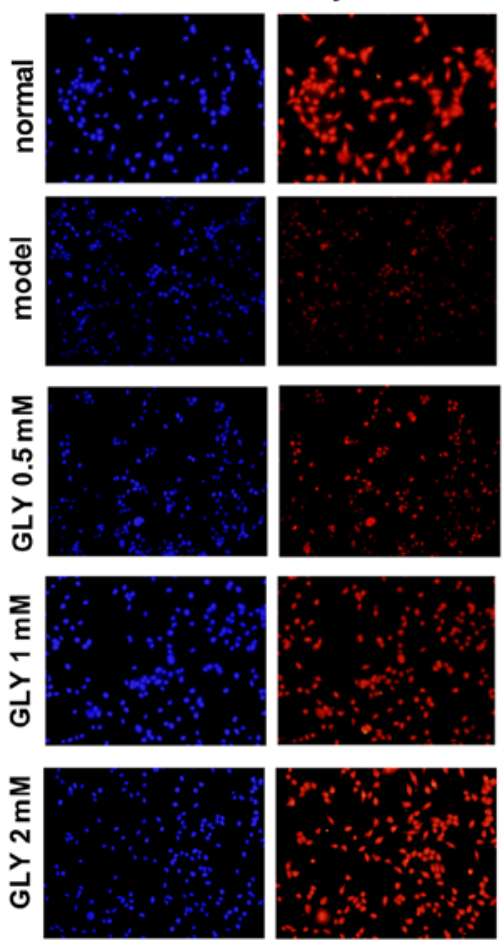

B

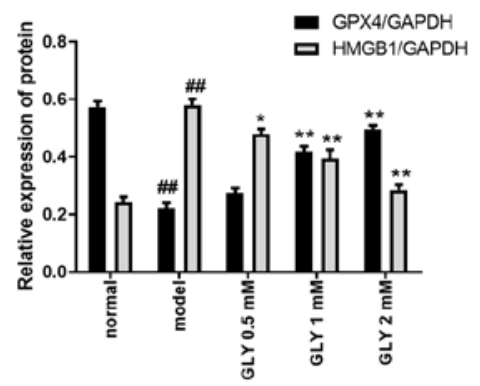

E merge
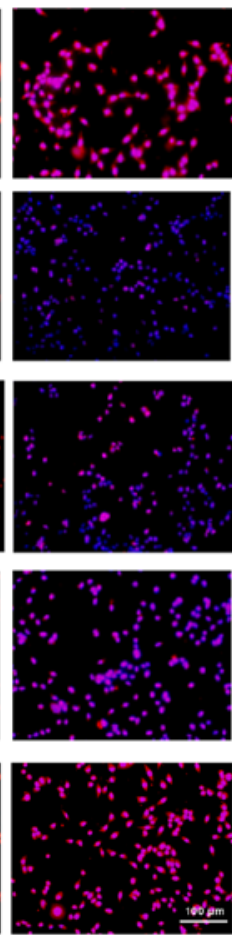

C

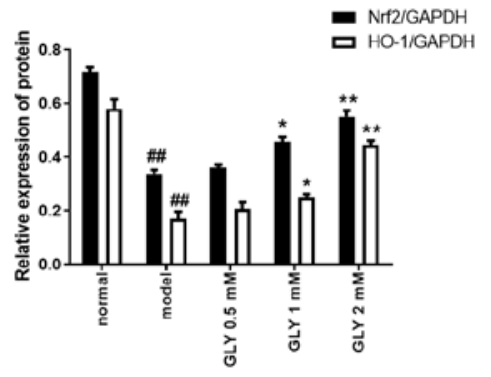

FITC-HMGB1
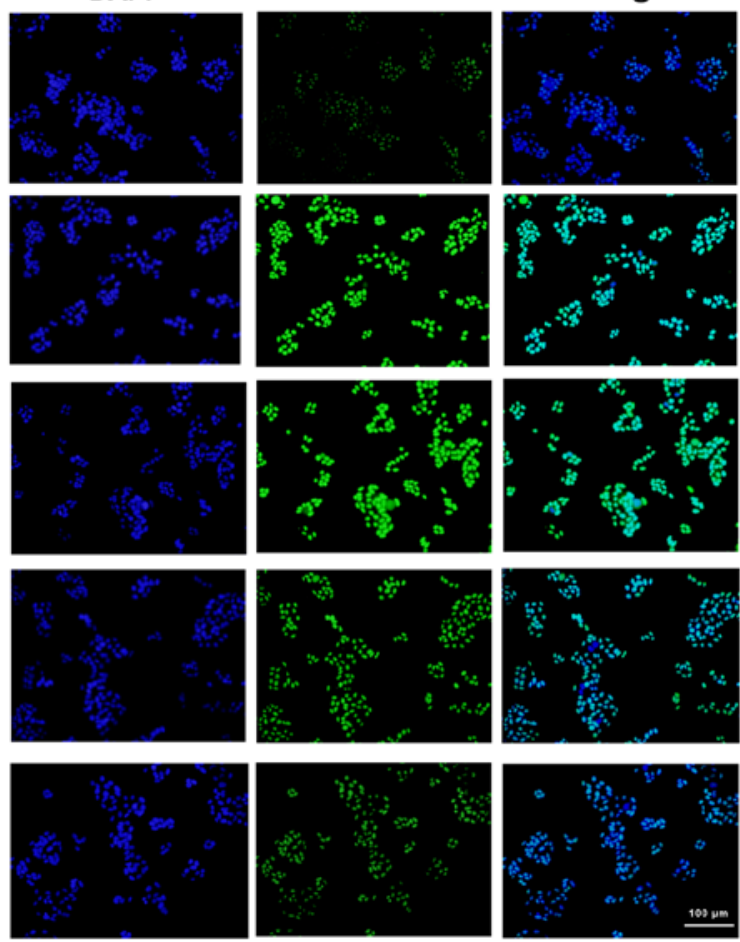

Figure 2. GLY increased GPX4 expression and promotes the Nrf2/HO-1/HMGB1 pathway in TNF- $\alpha$ /D-GalN induced L02 cells. (A) Protein levels of GPX4, HMGB1, Nrf2 and HO-1 were determined by western blotting. Quantification of (B) GPX4 and HMGB1, and (C) Nrf2 and HO-1. (D) GPX4 and (E) HMGB1 levels were detected by immunofluorescence in $\mathrm{L} 02$ cells. $\mathrm{n}=3$. ${ }^{\# \#} \mathrm{P}<0.01$ vs. normal; ${ }^{* *} \mathrm{P}<0.01,{ }^{*} \mathrm{P}<0.05$ vs. model. TNF- $\alpha$, tumour necrosis factor- $\alpha$; $\mathrm{D}-\mathrm{GalN}$, D-galactosamine; GLY, glycyrrhizin; GPX4, glutathione peroxidase 4; Nrf2, nuclear factor erythroid 2-related factor 2; HO-1, heme oxygenase-1; HMGB1, high mobility group protein B1.

antioxidant. GSH plays an important role in restoring liver function through removing lipid peroxides, including $\mathrm{O}^{2-}$, $\mathrm{H}_{2} \mathrm{O}_{2}$ and $\mathrm{LOOH}(17)$. Therefore, the level of GSH is an important factor in determining antioxidant capacity. $\mathrm{GSH}$ and $\mathrm{Fe}^{2+}$ are key regulators of ROS in the process of ferroptosis (18). In the process of ferroptosis, $\mathrm{Fe}^{2+}$ can convert lipid peroxide into ROS, and GPX4 converts lipid peroxide into the corresponding alcohol with the help of GSH (19). As shown in Fig. 1E and F, when compared with the normal group, the level of GSH was significantly decreased $(\mathrm{P}<0.01)$ and the $\mathrm{Fe}^{2+}$ level in the model group was significantly increased $(\mathrm{P}<0.01)$. After treatment with 1 or $2 \mathrm{mM}$ GLY, the levels of GSH were significantly increased $(\mathrm{P}<0.01)$ and the levels of $\mathrm{Fe}^{2+}$ were significantly decreased $(\mathrm{P}<0.01)$ compared with the model group. Therefore, it can be concluded that GLY downregulates the levels of ROS by promoting $\mathrm{GSH}$ and inhibiting $\mathrm{Fe}^{2+}$, thereby alleviating ferroptosis.

GLY increases GPX4 expression and promotes the Nrf2/HO-1/HMGB1 pathway in TNF- $\alpha / D$-GalN-induced LO2 cells. GPX4 competitively inhibits the production of ROS; when the activity of GPX4 is inhibited, the effect of ROS on ferroptosis is more subtle (20). As shown in Fig. 2A-C, when compared with the normal group, the protein levels of GPX4, Nrf2 and HO-1 in the model group were significantly reduced $(\mathrm{P}<0.01)$, while the protein level of HMGB1 in the model group was increased $(\mathrm{P}<0.01)$. After treatment with GLY, the levels of GPX4, Nrf2 and HO-1 were significantly increased, while the protein level of HMGB1 in the model group was significantly decreased. When compared with the normal group, the level of GPX4 in the model group was markedly reduced (Fig. 2D), 

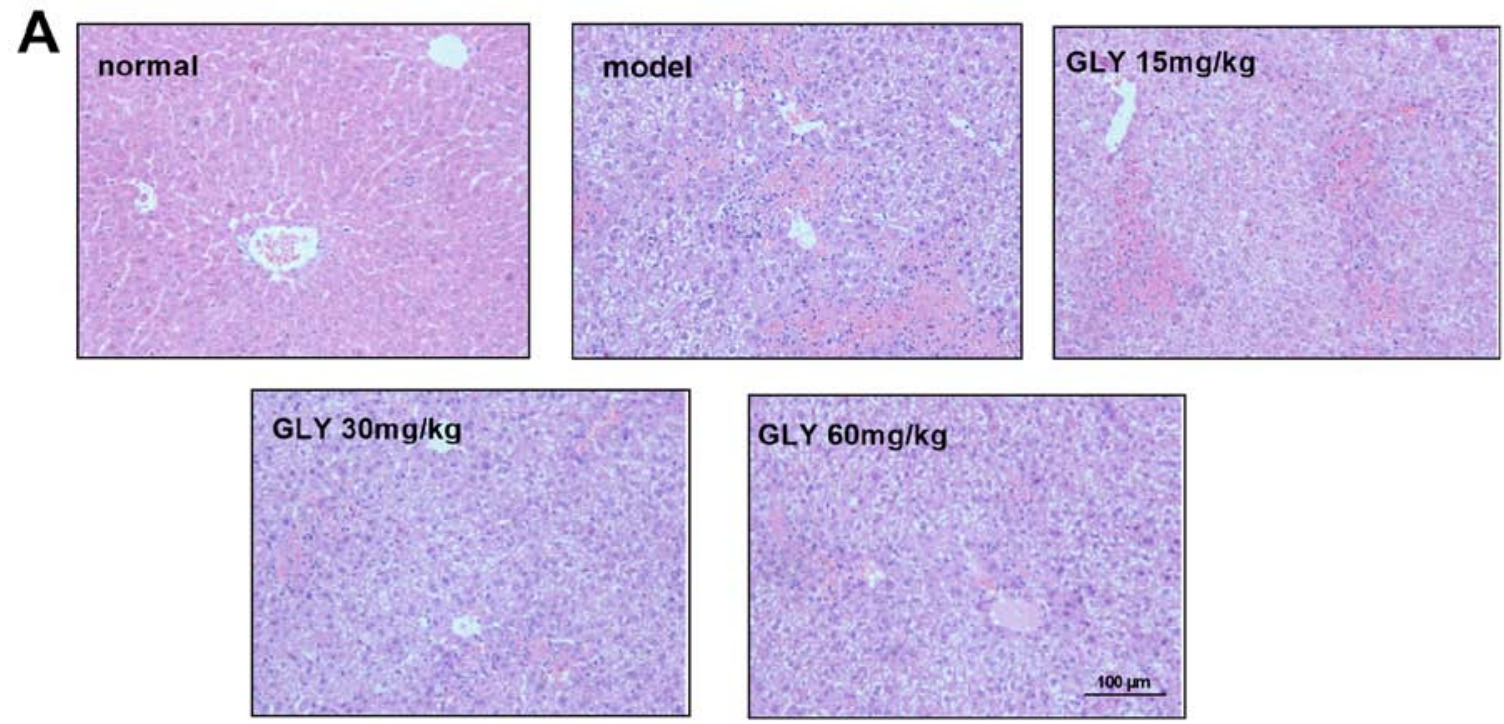

B

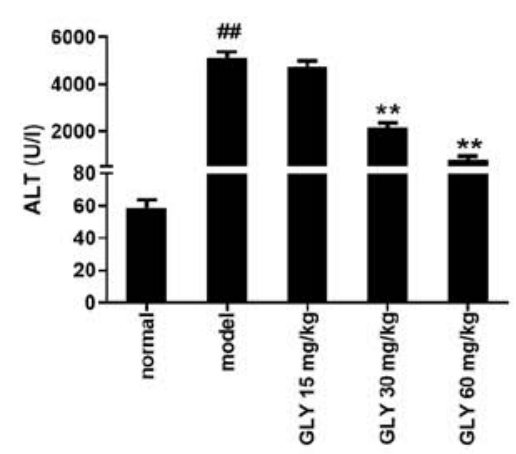

C

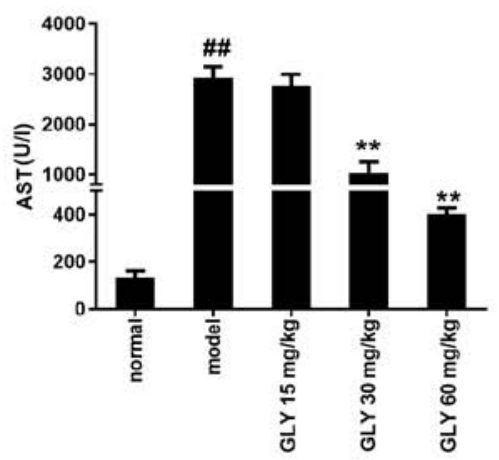

D

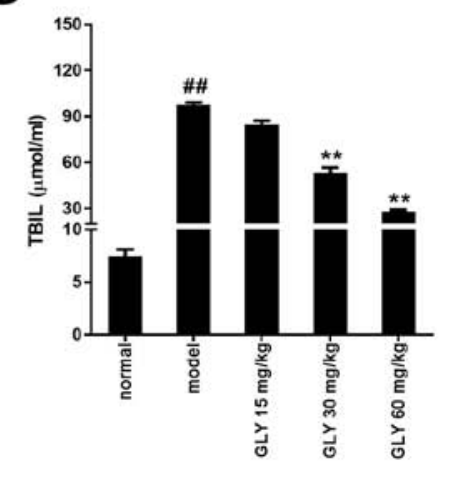

Figure 3. GLY alleviated pathological changes and liver function in LPS/D-GalN-induced ALF mice. (A) Pathological changes in the liver tissue were detected by hematoxylin and eosin staining. GLY reduced the pathological changes observed in the liver of LPS/D-GalN-induced ALF mice. GLY reduced the levels of (B) ALT, (C) AST and (D) TBIL in LPS/D-GalN-induced ALF mice. $\mathrm{n}=3$. ${ }^{\# \#} \mathrm{P}<0.01$ vs. normal; ${ }^{* *} \mathrm{P}<0.01$ vs. model. ALF, acute liver failure; LPS, lipopolysaccharide; D-GalN, D-galactosamine; GLY, glycyrrhizin; ALT, alanine aminotransferase; AST, aspartate aminotransferase; TBIL, total bilirubin.

while the level of HMGB1 in the model group was markedly increased (Fig. 2E), as determined by immunofluorescence analysis. After treatment with 1 or $2 \mathrm{mM} \mathrm{GLY}$, the level of GPX4 was increased, while the level of HMGB1 in model group was decreased.

GLY reduces pathological changes in the liver and improves liver function in ALF mice. As shown by the H\&E staining in Fig. 3A, the liver tissue in the normal group was clear and intact, with the liver plates neatly arranged. There were no signs of degeneration, necrosis or inflammatory cell infiltration. In the ALF model group, the structure of the liver tissue was disordered and the hepatocytes were necrotic. Inflammatory cell infiltration was also observed. The degree of liver cell damage in the GLY treatment groups was reduced compared with the model group. Inflammatory cell infiltration was also reduced. The degree of liver damage was lower following the higher doses of GLY. As shown in Fig. 3B-D the serum levels of ALT, AST and TBIL in the model group were significantly higher than those in the control group $(\mathrm{P}<0.01)$. Following treatment with GLY, the serum levels of ALT, AST and TBIL were significantly lower than those in the ALF model group; however, they were still higher than the normal group.

GLY enhances the anti-oxidative capacity of LPS/D-GalN-induced ALF mouse liver. As shown in Fig. 4A-C, when compared with the normal group, the levels of LDH, ROS and MDA in the model group were increased. After treatment with GLY, the levels of LDH, ROS and MDA were decreased.

GLY increases the level of GSH and decreases the level of $\mathrm{Fe}^{2+}$ in LPS/D-GalN-induced ALF mouse liver. As shown in Fig. 4D and E, when compared with the normal group, the level of GSH was significantly decreased $(\mathrm{P}<0.01)$, while the level of $\mathrm{Fe}^{2+}$ in the model group was significantly increased $(\mathrm{P}<0.01)$. After treatment with GLY, the level of GSH level was increased $(\mathrm{P}<0.01)$, while the level of $\mathrm{Fe}^{2+}$ significantly decreased $(\mathrm{P}<0.01)$.

GLY increases the expression of GPX4 and promotes the Nrf2/HO-1/HMGB1 pathway in LPS/D-GalN-induced ALF mouse liver. As shown in Fig. 5A-C, when compared with the 
A

B

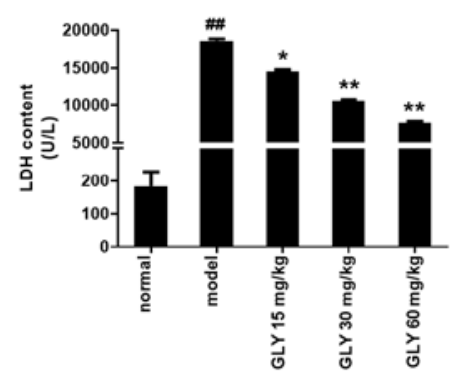

D

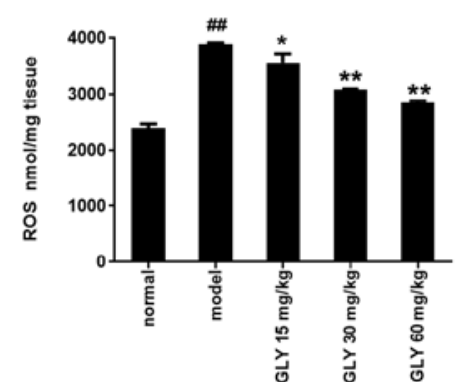

C

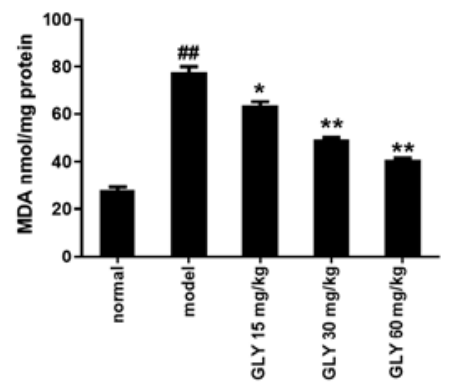

$\mathbf{E}$
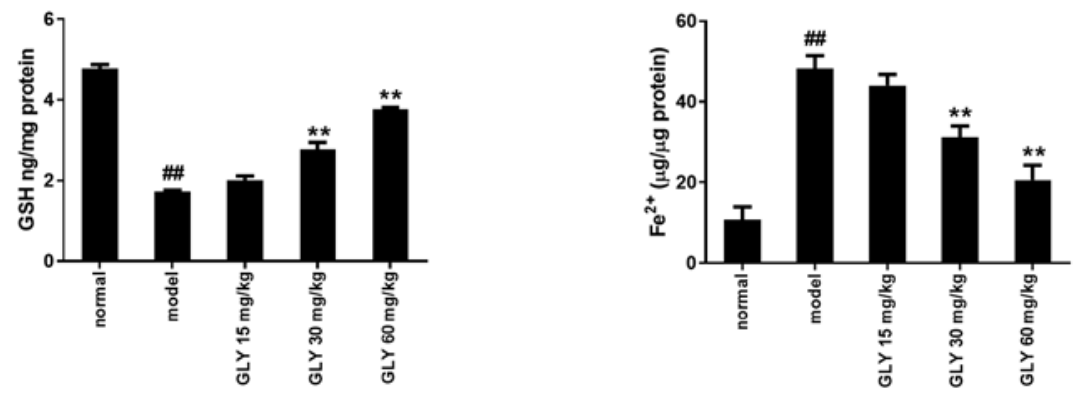

Figure 4. GLY decreased oxidative damage in LPS/D-GalN-induced ALF mice. GLY decreased the levels of (A) LDH, (B) ROS and (C) MDA, and increased the level of (D) GSH in LPS/D-GalN-induced ALF mice. (E) GLY decreased the level of $\mathrm{Fe}^{2+}$ in LPS/D-GalN-induced ALF mice. $\mathrm{n}=3$. ${ }^{\# \#} \mathrm{P}<0.01 \mathrm{vs}$. normal; ${ }^{* *} \mathrm{P}<0.01$, "P $<0.05$ vs. model. ALF, acute liver failure; LPS, lipopolysaccharide; D-GalN, D-galactosamine; GLY, glycyrrhizin; LDH, lactate dehydrogenase; ROS, reactive oxygen species; MDA, malondialdehyde; GSH, glutathione.

normal group, the expression levels of GPX4, Nrf2 and HO-1 in the model group were significantly decreased $(\mathrm{P}<0.01)$, while the expression of HMGB1 in the model group was significantly increased $(\mathrm{P}<0.01)$. After treatment with GLY, the levels of GPX4, Nrf2 and HO-1 were increased $(\mathrm{P}<0.01)$, while the level of HMGB1 was reduced. When compared with the normal group, the protein level of GPX4 in the model group was reduced, while the level of HMGB1 was increased, as determined by immunofluorescence (Fig. 5D). After treatment with GLY, the level of GPX4 was increased and the level of HMGB1 was decreased.

\section{Discussion}

LPS is present in the outer membrane of gram-negative bacteria. LPS consists of an endotoxin-like portion and a core sugar component, which consists of $\sim 10$ monosaccharides (21). In the pathogenesis of liver failure, enterogenous endotoxin can cause inflammatory cells to secrete TNF- $\alpha$, further damaging the liver cells; this is known as the 'two-hit' theory (3). Liver injury induced through the 'two-hit' mechanism is more serious than that caused by LPS alone. LPS or TNF- $\alpha$ alone cause a lower specific damage to hepatocytes (21). Previous studies have shown that D-GalN can be used as a sensitizer in LPS-induced liver injury; specifically, uridine triphosphate is depleted by the galactose pathway, which inhibits protein synthesis, resulting in ROS-mediated liver damage (22-24).
Therefore, LPS can be used in combination with D-GalN to induce ALF in animal models $(25,26)$ and TNF- $\alpha$ combined with D-GalN can be used to create an L02 cell injury model (27); these models have been widely used to explore and develop new liver protection agents for the treatment of ALF.

Ferroptosis is a type of cell death that is distinct from apoptosis, necrosis, pyroptosis and autophagy. As is shown in Fig. 6, ferroptosis is predominantly characterized by iron homeostasis and ROS. Therefore, Dixon et al (4) named this mechanism of cell death ferroptosis. The morphological changes that occur are due to decreased mitochondrial volume, increased lipid bilayer membrane density and the decrease or disappearance of mitochondria (28). Research into the mechanism of ferroptosis predominantly focuses on the imbalance of iron homeostasis and the decreased activity of GPX4 (29). Circulating iron in the body mainly binds to transferrin and exists as $\mathrm{Fe}^{3+} . \mathrm{Fe}^{3+}$ enters cells through the membrane protein transferrin receptor 1 (30). $\mathrm{Fe}^{3+}$ is reduced to $\mathrm{Fe}^{2+}$ by iron oxidoreductase six-transmembrane epithelial antigen of the prostate 3 (31). In an unbalanced state, the level of $\mathrm{Fe}^{2+}$ increases inside cells, which is an important factor in the process of ferroptosis. The key process of ferroptosis is the Fenton reaction, in which $\mathrm{Fe}^{2+}$ converts lipid peroxide into ROS. While GPX4 converts lipid peroxide into the corresponding alcohol with the help of GSH (19). The ROS produced by this process could cause oxidatively damage and cell death. At the same time, GPX4 competitively inhibits the production of ROS, and when its 
A

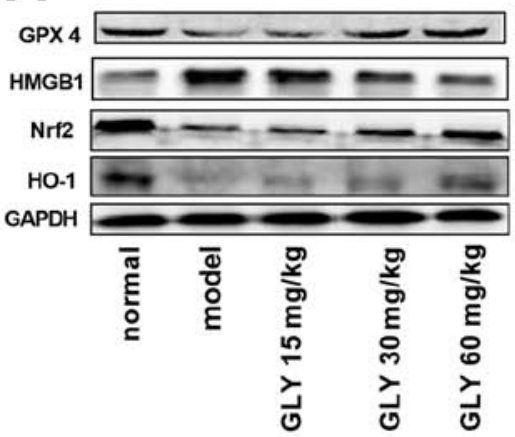

B

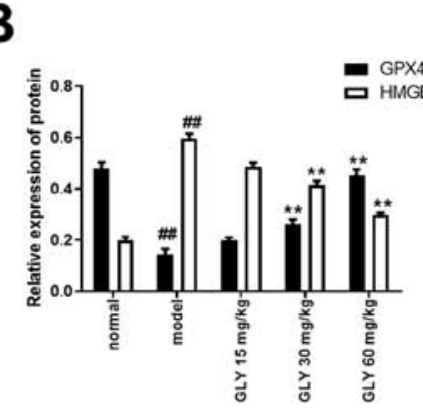

C

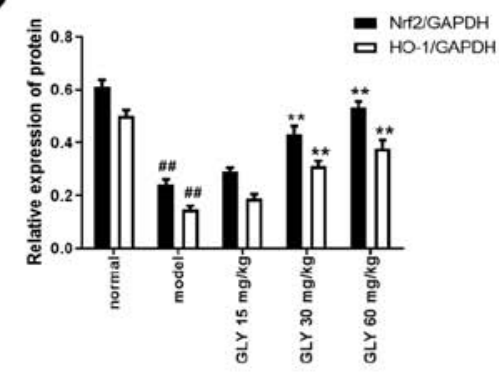

D

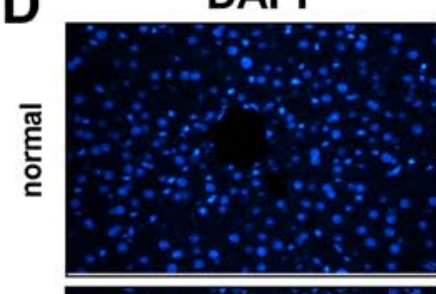

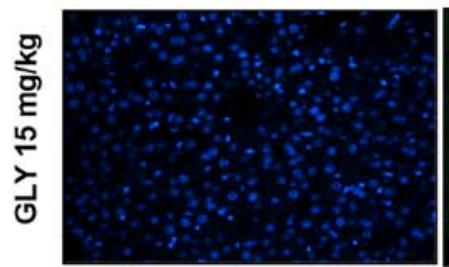
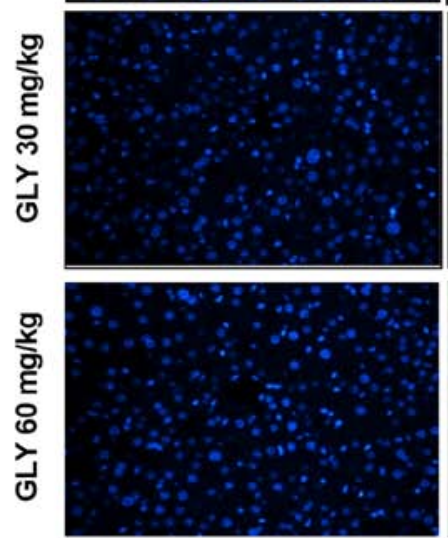

FITC-GPX4
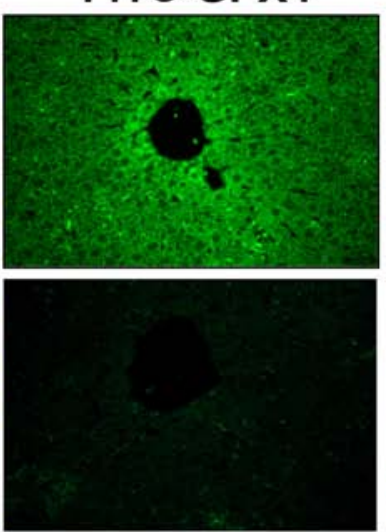

cy3-HMGB1
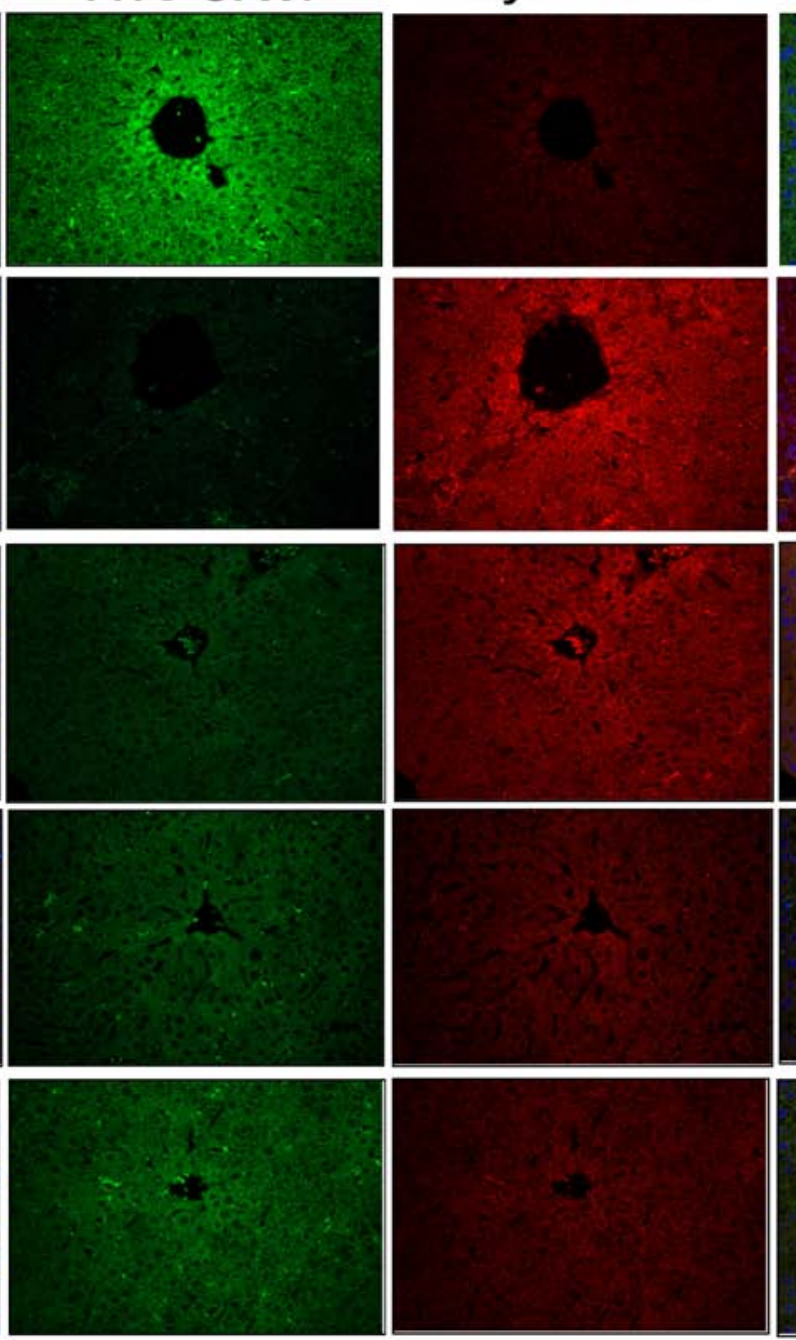
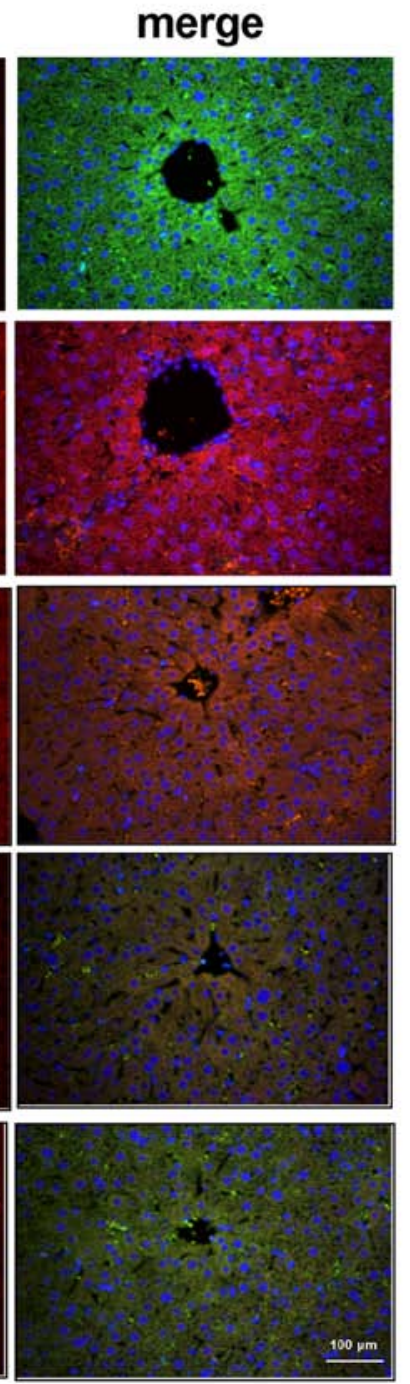

Figure 5. GLY increases the expression of GPX4 and promotes the Nrf2/HO-1/HMGB1 pathway in LPS/D-GalN-induced ALF mice. (A) Protein levels of GPX4, HMGB1, Nrf2 and HO-1 were determined by western blotting. Quantification of (B) GPX4 and HMGB1, and (C) Nrf2 and HO-1. (D) Protein levels of GPX4 and HMGB1 were determined by immunofluorescence in LPS/D-GalN-induced ALF mice. $n=3 .{ }^{\# \#} \mathrm{P}<0.01$ vs. normal; ${ }^{* *} \mathrm{P}<0.01$ vs. model. LPS, lipopolysaccharide; D-GalN, D-galactosamine; ALF, acute liver failure; GLY, glycyrrhizin; GPX4, glutathione peroxidase 4; Nrf2, nuclear factor erythroid 2-related factor 2; HO-1, heme oxygenase-1; HMGB1, high mobility group protein B1.

activity is inhibited, ferroptosis occurs (20). Therefore, the excessive production of ROS is important to induce ferroptosis. Moreover, the detection of ferroptosis has no specific indicators (32). The changes to the levels of GPX4, $\mathrm{Fe}^{2+}, \mathrm{GSH}$ and ROS could be combined to define ferroptosis.

Research into ferroptosis in liver disease is predominantly focused on the regulation of oxidative stress, focusing on hepatocellular carcinoma and drug-induced liver injury. It has been reported that sorafenib can induce ferroptosis in tumor cells through the p62-kelch-like ECH-associated protein 1-NRF2 pathway to achieve anti-tumor efficacy (33). Acetaminophen can aggravate oxidative stress and induce ferroptosis (34). In addition, survival is increased in vitamin E-fed GPX4-deficient mouse models by inhibiting lipid 


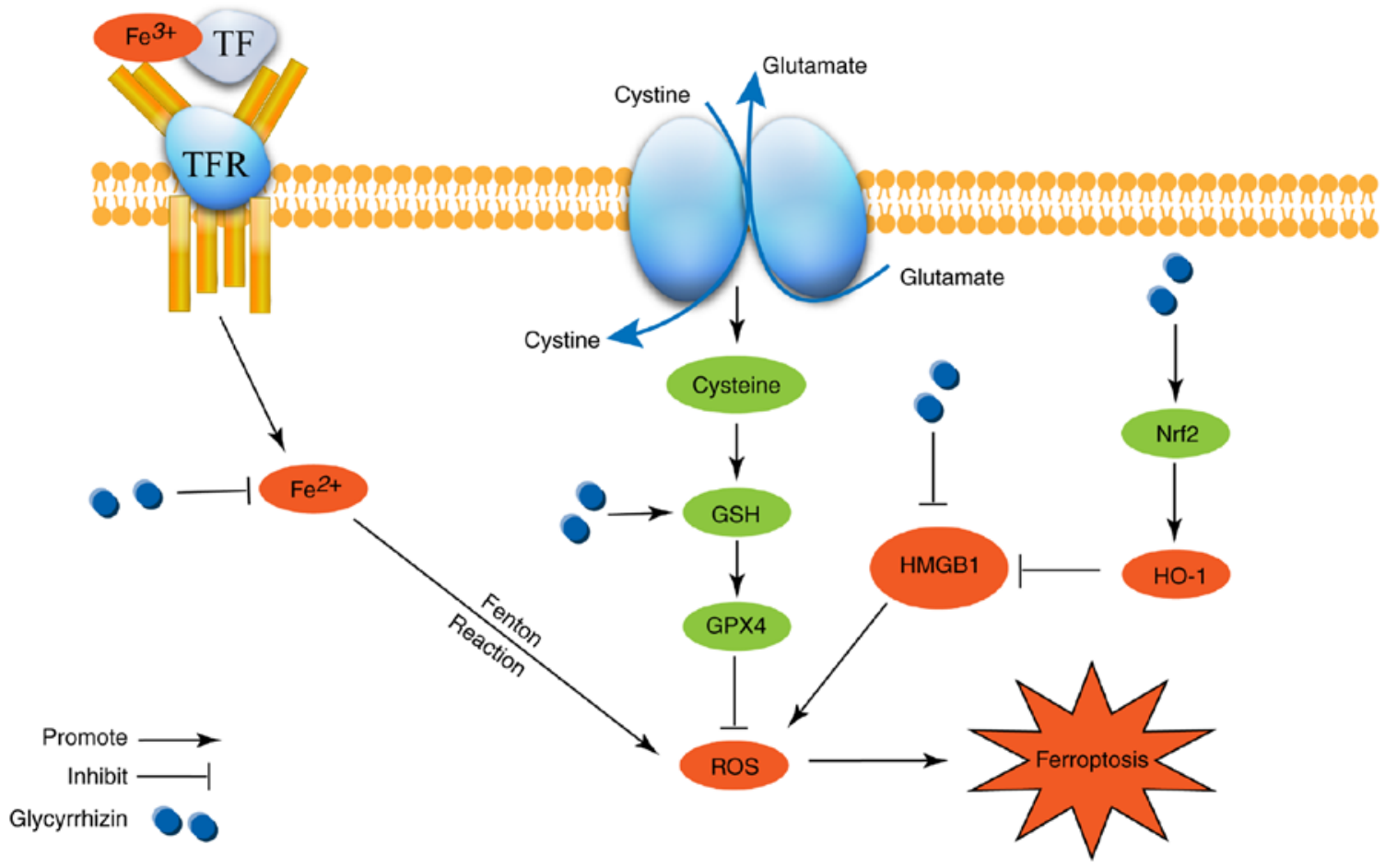

Figure 6. Inhibitory effect of glycyrrhizin on ferroptosis during acute liver failure functions by promoting the Nrf2/HO-1/HMGB1 signaling pathway. TF, transferrin; TRF, transferrin receptor; GSH, glutathione; GPX4, glutathione peroxidase 4; Nrf2, nuclear factor erythroid 2-related factor 2; HO-1, heme oxygenase-1; HMGB1, high mobility group protein B1; ROS, reactive oxygen species.

oxidation (35). Oxidative stress caused by ROS and other free radicals/oxidants plays an important role in the pathogenesis of atherosclerosis, diabetes, ischemic stroke and related central nervous system diseases $(36,37)$. When the body is damaged by oxidation, various anti-oxidant molecules and enzymes can be produced to remove the ROS generated, and protect the body from ROS damage (38). GSH is an important non-enzymatic antioxidant in the body. GSH content is an important biomarker for measuring antioxidant capacity, while LDH can be used as a cell damage marker (37). GSH is an important cofactor for GPX4. When the synthesis of GSH synthesis is blocked, the activity of GPX4 is decreased, as is the cellular antioxidant capacity, which leads to the accumulation of ROS and promotes ferroptosis (39). Nrf2 is also an important endogenous antioxidant mechanism. By activating Nrf2, the expression of downstream signaling molecules, such as HO-1, can be induced to exert an anti-oxidative stress response (40). Previous studies have shown that the upregulation of the Nrf2/HO-1 signaling pathway, and inhibition of HMGB1 expression, has an anti-inflammatory effect, attenuating ischemia-reperfusion injury and providing cell protection (41-43). HMGB1 is a potent inflammatory factor that plays a key role in the initiation and maintenance of inflammatory cascade responses $(44,45)$. Large amounts of hepatocyte necrosis during liver failure can lead to the release of HMGB1 from hepatocytes, as HMGB1 has a similar effect to endotoxin, HMGB1 is also involved in the pathogenesis of ALF (46). Furthermore, the exposure of normal human bronchial epithelial cells to HMGB1 resulted in an increase in the levels of ROS (47). Therefore, if oxidative stress can be prevented through the Nrf2/HO-1/HMGB1 pathway to inhibit ferroptosis, ALF can be alleviated.
GLY acts as an anti-inflammatory, anti-oxidant and immune-regulator and can protect hepatocytes. As a chronic hepatitis drug, GLY has been used in clinical practice for many years with good therapeutic effects $(12,48)$. Previous studies have shown that GLY could exert a good effect on alcoholic liver disease (49), non-alcoholic fatty liver disease (50), intrahepatic cholestasis (51), metabolic syndrome-induced liver damage (52), acute liver injury (53), liver fibrosis (11) and hepatocellular carcinoma (54).

GLY is a verified selective inhibitor of HMGB1 (55). GLY directly binds to HMG boxes, blocking HMGB1 release into the extracellular space. The specific mechanism involves the interaction of GLY with two shallow concave surfaces formed by the two arms of the HMG boxes $(55,56)$. Our previous study showed that HMGB1 plays an important role in the development of ALF (57). High expression of HMGB1 is present in patients with liver failure caused by chronic hepatitis B virus (HBV) infection. HMGB1 is involved in the inflammatory response during liver failure by inhibiting the activity of T regulatory cells in chronically infected HBV (57). However, the relationship between HMGB1 and ferroptosis in ALF is still unclear. GLY has been rarely reported in the study of ALF and ferroptosis in ALF. In the present study, when L02 cell and mouse models of ALF were induced using TNF- $\alpha / D-G a l N$ or LPS/D-GalN, respectively, the levels of GSH GPX4, and cell viability were decreased in the cell and mouse models of ALF compared with the normal group, $\mathrm{Fe}^{2+}$ and ROS levels were increased. The changes in these molecules indicated that the ferroptosis/ALF model had been successfully induced. Moreover, the levels of MDA and LDH were increased, and the Nrf2/HO-1/HMGB1 pathway was inhibited, supporting the hypothesis of oxidative stress injury 
in ferroptosis. The severity of the histopathologic changes in the liver of the model group mice was notable. Serum ALT, AST and TBIL levels were increased. However, after treatment with GLY, the degree of liver damage was reduced, the level of HMGB1 was also reduced, and the levels of GPX4, Nrf2 and HO-1 were increased. The levels of $\mathrm{LDH}, \mathrm{Fe}^{2+}$, MDA and ROS were decreased by GLY treatment. The level of GSH was increased by GLY treatment, as was cell viability. The results of the present study are consistent with those of a previous study that found GLY could ameliorate obesity by activating the Nrf2/HO-1 pathway (58). After treatment with GLY, the severity of the histopathologic changes observed in the liver was reduced. Serum ALT, AST and TBIL levels were decreased by GLY. Therefore, the present study indicated that GLY could increase anti-oxidative capacity, GSH and GPX4 levels, and active the Nrf2/HO-1/HMGB1 pathway, inhibiting ferroptosis in an LPS/D-GalN-induced ALF model.

In conclusion, GLY reduced the level of ferroptosis during ALF, and the mechanism may depend on the inhibition of the oxidative stress pathway. However, the pharmacological effects of GLY are diverse. From the present study, it was found that GLY plays a role in multiple aspects of ferroptosis in ALF, including the regulation of the level of $\mathrm{Fe}^{2+}$, the GSH/GPX4 pathway and the Nrf2/HO-1/HMGB1 pathway (Fig. 6). These three functions of GLY would inhibit ROS accumulation, inhibiting ferroptosis and alleviating ALF. In the future, the specific mechanisms of GLY in the process of ferroptosis and liver failure should be addressed. The present study provides a scientific basis for the treatment of ALF and the inhibition of ferroptosis.

\section{Acknowledgements}

Not applicable.

\section{Funding}

The present study was supported by the Natural Science Foundation of China (grant no. 81870413).

\section{Availability of data and materials}

All data generated or analyzed during this study are included in this published article.

\section{Authors' contributions}

ZG and YW conceived and designed the experiments. YW, QC, CS and FJ performed the experiments. YW analyzed the data. QC and CS contributed reagents/materials/analysis tools. YW wrote the paper. ZG edited the article. All authors read and approved the final version of the manuscript and agree to take responsibility for the published article.

\section{Ethics approval and consent to participate}

The present study was approved by The Institutional Animal Care and Use Committee of Renmin Hospital of Wuhan University.

\section{Patient consent for publication}

Not applicable.

\section{Competing interests}

The authors declare that they have no competing interests.

\section{References}

1. Bernal W, Auzinger G, Dhawan A and Wendon J: Acute liver failure. Lancet 376: 190-201, 2010.

2. Liu Y, Wang Y, Chen Q, Jiao F, Wang L and Gong Z: HDAC2 inhibitor CAY10683 reduces intestinal epithelial cell apoptosis by inhibiting mitochondrial apoptosis pathway in acute liver failure. Histol Histopathol 29: 18120, 2019.

3. Wang Y, Chen H, Chen Q, Jiao FZ, Zhang WB and Gong ZJ: The protective mechanism of CAY10683 on intestinal mucosal barrier in acute liver failure through LPS/TLR4/MyD88 pathway. Mediators Inflamm 13: 7859601, 2018.

4. Dixon SJ, Lemberg KM, Lamprecht MR, Skouta R, Zaitsev EM, Gleason CE, Patel DN, Bauer AJ, Cantley AM, Yang WS, et al: Ferroptosis: An iron-dependent form of nonapoptotic cell death. Cell 149: 1060-1072, 2012.

5. Wei L, Ren F, Zhang X, Wen T, Shi H, Zheng S, Zhang J, Chen Y, Han Y and Duan Z: Oxidative stress promotes D-GalN/LPS-induced acute hepatotoxicity by increasing glycogen synthase kinase $3 \beta$ activity. Inflamm Res 63: 485-494, 2014.

6. Mishra D, Jain N, Rajoriya V and Jain AK: Glycyrrhizin conjugated chitosan nanoparticles for hepatocyte-targeted delivery of lamivudine. J Pharm Pharmacol 66: 1082-1093, 2014.

7. Nazari S, Rameshrad M and Hosseinzadeh H: Toxicological effects of glycyrrhiza glabra (Licorice): A review. Phytother Res 31: 1635-1650, 2017.

8. Michaelis M, Geiler J, Naczk P, Sithisarn P, Leutz A, Doerr HW and Cinatl J Jr: Glycyrrhizin exerts antioxidative effects in H5N1 influenza A virus-infected cells and inhibits virus replication and pro-inflammatory gene expression. PLoS One 6: e19705, 2011.

9. Ojha S, Javed H, Azimullah S, Abul Khair SB and Haque ME: Glycyrrhizic acid attenuates neuroinflammation and oxidative stress in rotenone model of parkinson's disease. Neurotox Res 29: 275-287, 2016.

10. Wang XR, Hao HG and Chu L: Glycyrrhizin inhibits LPS-induced inflammatory mediator production in endometrial epithelial cells. Microb Pathog 109: 110-113, 2017.

11. Zhou Y, Tong X, Ren S, Wang X, Chen J, Mu Y, Sun M, Chen G, Zhang $\mathrm{H}$ and Liu P: Synergistic anti-liver fibrosis actions of total astragalus saponins and glycyrrhizic acid via TGF- $\beta 1 /$ Smads signaling pathway modulation. J Ethnopharmacol 190: 83-90, 2016.

12. Lin CC and Wang PH: Intravenous glycyrrhizin improved serum transaminases rapidly in a chronic hepatitis B patient with acute exacerbation. J Formosan Med Assoc 114: 188-189, 2015.

13. Kong ZH, Chen X, Hua HP, Liang L and Liu LJ: The oral pretreatment of glycyrrhizin prevents surgery-induced cognitive impairment in aged mice by reducing neuroinflammation and alzheimer's-related pathology via HMGB1 inhibition. J Mol Neurosci 63: 385-395, 2017.

14. Mittler R, Vanderauwera S, Suzuki N, Miller G, Tognetti VB, Vandepoele K, Gollery M, Shulaev V and Van Breusegem F: ROS signaling: The new wave? Trends Plant Sci 16: 300-309, 2011.

15. Xie Y, Hou W, Song X, Yu Y, Huang J, Sun X, Kang R and Tang D: Ferroptosis: Process and function. Cell Death Differ 23: 369-379, 2016.

16. Barrera G, Pizzimenti S, Daga M, Dianzani C, Arcaro A Cetrangolo GP, Giordano G, Cucci MA, Graf M and Gentile F: Lipid peroxidation-derived aldehydes, 4-hydroxynonenal and malondialdehyde in aging-related disorders. Antioxidants (Basel) 30: 8, 2018.

17. Levine WG: Glutathione and hepatic mixed-function oxidase activity. Drug Metab Rev 14: 909-930, 1983.

18. Du J, Wang T, Li Y, Zhou Y, Wang X, Yu X, Ren X, An Y, Wu Y, Sun W, et al: DHA inhibits proliferation and induces ferroptosis of leukemia cells through autophagy dependent degradation of ferritin. Free Radic Biol Med 131: 356-369, 2019 
19. Proneth B and Conrad M: Ferroptosis and necroinflammation, a yet poorly explored link. Cell Death Differ 26: 14-24, 2019.

20. Latunde-Dada GO: Ferroptosis: Role of lipid peroxidation, iron and ferritinophagy. Biochimica Biophysica Acta Gen Subj 1861: $1893-1900,2017$

21. Hamesch K, Borkham-Kamphorst E, Strnad P and Weiskirchen R: Lipopolysaccharide-induced inflammatory liver injury in mice. Lab Anim 49: 37-46, 2015.

22. Maes M, Vinken M and Jaeschke H: Experimental models of hepatotoxicity related to acute liver failure. Toxicol Appl Pharmacol 290: 86-97, 2016.

23. Zhuo T, Zhou S, Zhang W, Lambertucci C and Volpini R: Synthesis and ability of new ligands for $\mathrm{G}$ protein-coupled receptors 17 (GPR17). Med Sci Monit 23: 953-959, 2017.

24. Song J, Lu C, Zhao W and Shao X: Melatonin attenuates TNF- $\alpha$-mediated hepatocytes damage via inhibiting mitochondrial stress and activating the Akt-Sirt3 signaling pathway. J Cell Physiol 234: 20969-20979, 2019.

25. Shang Y, Liu Y, Du L, Wang Y, Cheng X, Xiao W, Wang X, Jin $\mathrm{H}$, Yang $\mathrm{X}$, Liu $\mathrm{S}$ and Chen Q: Targeted expression of uncoupling protein 2 to mouse liver increases the susceptibility to lipopolysaccharide/galactosamine-induced acute liver injury. Hepatology 50: 1204-1216, 2009.

26. Chai FN, Zhang J, Xiang HM, Xu HS, Li YF, Ma WY, Li XG and Ye XL: Protective effect of coptisine from rhizoma coptidis on LPS/D-GalN-induced acute liver failure in mice through up-regulating expression of miR-122. Biomed Pharmacother 98 : 180-190, 2018

27. Yan X, Jiang Z, Bi L, Yang Y and Chen W: Salvianolic acid A attenuates TNF- $\alpha$ - and D-GalN-induced ER stress-mediated and mitochondrial-dependent apoptosis by modulating Bax/Bcl-2 ratio and calcium release in hepatocyte LO2 cells. Naunyn Schmiedebergs. Arch Pharmacol 388: 817-830, 2015.

28. Yu H, Guo P, Xie X, Wang Y and Chen G: Ferroptosis, a new form of cell death, and its relationships with tumourous diseases. J Cell Mol Med 21: 648-657, 2017.

29. Yoshida M, Minagawa S, Araya J, Sakamoto T, Hara H, Tsubouchi K, Hosaka Y, Ichikawa A, Saito N, Kadota T, et al: Involvement of cigarette smoke-induced epithelial cell ferroptosis in COPD pathogenesis. Nat Commun 10: 3145, 2019.

30. Anderson GJ and Frazer DM: Current understanding of iron homeostasis. Am J Clin Nutr 106 (Suppl 6): 1559S-1566S, 2017.

31. Gauss GH, Kleven MD, Sendamarai AK, Fleming MD and Lawrence CM: The crystal structure of six-transmembrane epithelial antigen of the prostate 4 (Steap4), a ferri/cuprireductase, suggests a novel interdomain flavin-binding site. J Biol Chem 288: 20668-20682, 2013.

32. Chen D, Eyupoglu IY and Savaskan N: Ferroptosis and cell death analysis by flow cytometry. Methods Mol Biol 1601: 71-77, 2017.

33. Sun X, Ou Z, Chen R, Niu X, Chen D, Kang R and Tang D: Activation of the p62-Keap1-NRF2 pathway protects against ferroptosis in hepatocellular carcinoma cells. Hepatology 63 173-184, 2016

34. Hu J, Kholmukhamedov A, Lindsey CC, Beeson CC, Jaeschke H and Lemasters JJ: Translocation of iron from lysosomes to mitochondria during acetaminophen-induced hepatocellular injury: Protection by starch-desferal and minocycline. Free Radic Bio Med 97: 418-426, 2016.

35. Carlson BA, Tobe R, Yefremova E, Tsuji PA, Hoffmann VJ, Schweizer U, Gladyshev VN, Hatfield DL and Conrad M Glutathione peroxidase 4 and vitamin E cooperatively prevent hepatocellular degeneration. Redox Biol 9: 22-31, 2016.

36. Ritchie RH, Drummond GR, Sobey CG, De Silva TM and Kemp-Harper BK: The opposing roles of NO and oxidative stress in cardiovascular disease. Pharmacol Res 116: 57-69, 2017.

37. Niemann B, Rohrbach S, Miller MR, Newby DE, Fuster V and Kovacic JC: Oxidative stress and cardiovascular risk: Obesity, diabetes, smoking, and pollution part 3 of a 3-part series. J Am Coll Cardiol 70: 230-251, 2017.

38. Henchcliffe $\mathrm{C}$ and Beal MF: Mitochondrial biology and oxidative stress in parkinson disease pathogenesis. Nature Clin Pract Neurol 4: 600-609, 2008

39. Maiorino M, Conrad M and Ursini F: GPx4, Lipid peroxidation, and cell death: Discoveries, rediscoveries, and open issues. Antioxid Redox Signal 29: 61-74, 2018.

40. Ma Q: Role of nrf2 in oxidative stress and toxicity. Annu Rev Pharmacol Toxicol 53: 401-426, 2013.
41. Chang CY, Kao TK, Chen WY, Ou YC, Li JR, Liao SL, Raung SL and Chen CJ: Tetramethylpyrazine inhibits neutrophil activation following permanent cerebral ischemia in rats. Biochem Biophys Res Commun 463: 421-427, 2015.

42. Kim SR, Ha YM, Kim YM, Park SW, Kim HJ, Chung HT and Chang KC: Ascorbic acid reduces HMGB1 secretion in lipopolysaccharide-activated RAW 264.7 cells and improves survival rate in septic mice by activation of $\mathrm{Nrf} 2 / \mathrm{HO}-1$ signals. Biochem Pharmacol 95: 279-289, 2015.

43. Liu C, Zhu C, Wang G, Xu R and Zhu Y: Higenamine regulates Nrf2-HO-1-Hmgbl axis and attenuates intestinal ischemia-reperfusion injury in mice. Inflammation Res 64: 395-403, 2015.

44. Andersson U and Tracey KJ: HMGB1 is a therapeutic target for sterile inflammation and infection. Ann Rev Immunol 29: 139-162, 2011.

45. Yu M, Wang HC, Ding AH, Golenbock DT, Latz E, Czura CJ, Fenton MJ, Tracey KJ and Yang H: HMGB1 signals through toll-like receptor (TLR) 4 and TLR2. Shock 26: 174-179, 2006.

46. Yang RK, Zou XP, Tenhunen J and Tonnessen TI: HMGB1 and extracellular histones significantly contribute to systemic inflammation and multiple organ failure in acute liver failure. Mediators Inflamm 2017: 5928078, 2017.

47. Lv YH, Li YL, Zhang DD, Zhang AB, Guo WH and Zhu SF: HMGB1-induced asthmatic airway inflammation through GRP75-mediated enhancement of ER-mitochondrial $\mathrm{Ca}^{2+}$ transfer and ROS increased. J Cell Biochem 119: 4205-4215, 2018.

48. Carreno V: Review article: Management of chronic hepatitis C in patients with contraindications to anti-viral therapy. Aliment Pharmacol Ther 39: 148-162, 2014

49. Milosevic N, Milanovic M, Turkulov V, Medic-Stojanoska M, Abenavoli $\mathrm{L}$ and Milic N: May patients with alcohol liver disease benefit from herbal medicines? Rev Recent Clin Trials 11: 227-237, 2016.

50. Sun X, Duan X, Wang C, Liu Z, Sun P, Huo X, Ma X, Sun H, Liu K and Meng Q: Protective effects of glycyrrhizic acid against non-alcoholic fatty liver disease in mice. Eur J Pharmacol 806: 75-82, 2017

51. Wang H, Fang ZZ, Meng R, Cao YF, Tanaka N, Krausz KW and Gonzalez FJ: Glycyrrhizin and glycyrrhetinic acid inhibits alpha-naphthyl isothiocyanate-induced liver injury and bile acid cycle disruption. Toxicology 386: 133-142, 2017.

52. Sil R, Ray D and Chakraborti AS: Glycyrrhizin ameliorates metabolic syndrome-induced liver damage in experimental rat model. Mol Cell Biochem 409: 177-189, 2015.

53. Yan T, Wang H, Zhao M, Yagai T, Chai Y, Krausz KW, Xie C, Cheng X, Zhang J, Che Y, et al: Glycyrrhizin protects against acetaminophen-induced acute liver injury via alleviating tumor necrosis factor $\alpha$-mediated apoptosis. Drug Metab Dispos 44: 720-731, 2016

54. Zhang X, Yang H, Yue S, He G, Qu S, Zhang Z, Ma B, Ding R, Peng W, Zhang H, et al: The mTOR inhibition in concurrence with ERK $1 / 2$ activation is involved in excessive autophagy induced by glycyrrhizin in hepatocellular carcinoma. Cancer Med 6: 1941-1951, 2017.

55. Mollica L, De Marchis F, Spitaleri A, Dallacosta C, Pennacchini D, Zamai M, Agresti A, Trisciuoglio L, Musco G and Bianchi ME: Glycyrrhizin binds to high-mobility group box 1 protein and inhibits its cytokine activities. Chem Biol 14: 431-441, 2007.

56. Li YJ, Wang L, Zhang B, Gao F and Yang CM: Glycyrrhizin, an HMGB1 inhibitor, exhibits neuroprotective effects in rats after lithium-pilocarpine-induced status epilepticus. J Pharm Pharmacol 71: 390-399, 2019.

57. Wang LW, Chen $\mathrm{H}$ and Gong ZJ: High mobility group box-1 protein inhibits regulatory $\mathrm{T}$ cell immune activity in liver failure in patients with chronic hepatitis B. Hepatobiliary Pancreat Dis Int 9: 499-507, 2010

58. Abo El-Magd NF,El-Mesery M,El-Karef A and El-Shishtawy MM: Glycyrrhizin ameliorates high fat diet-induced obesity in rats by activating NrF2 pathway. Life Sci 193: 159-170, 2018.

This work is licensed under a Creative Commons Attribution-NonCommercial-NoDerivatives 4.0 International (CC BY-NC-ND 4.0) License. 